\title{
EDUCAÇÃO, UMA PROPOSTA DE “RE-DESTINAÇÃO” ANTROPOLÓGICA: NOTAS ACERCA DO PENSAMENTO EXISTENCIALISTA CRISTÃO DE JUVENAL ARDUINI
}

\section{EDUCATION, A PROPOSAL OF ANTHROPOLOGICAL "RE-ASSIGNMENT": NOTES ON THE CHRISTIAN EXISTENTIALIST THOUGHT OF JUVENAL ARDUINI}

\begin{abstract}
Washington Abadio da Silva ${ }^{1}$
Resumo: Este artigo aponta elementos constantes de duas obras de Monsenhor Juvenal Arduini, bem como apresenta dados da vida e formação do autor. Padre e educador, ele discute, em "Destinação Antropológica" e "Ética Responsável e Criativa", temas de interesse e inegável relevância na área da educação. Com efeito, sua reflexão ético-antropológica insere-se no contexto maior do debate sobre a educação brasileira, em geral, e a que se desenvolve no ensino superior. Juvenal Arduini, a partir da antropologia e da ética, defende uma visão de homem como construtor e protagonista de seu destino, capaz de responder de modo pessoal e em espírito de diálogo aos problemas e desafios com os quais se depara no cotidiano. Com responsabilidade e criatividade, a pessoa e a humanidade colhem frutos bons de toda prática advinda da inter-comunicação. Manifestando sua identidade pela linguagem, inclusive pela capacidade de fecundo silêncio, pode o homem, educador e educando em constante crescimento, contribuir para a efetivação de uma sociedade mais justa, em que as pessoas possam viver de forma mais livre e responsável. O existencialismo cristão do autor revela-o capaz de admirável síntese entre o compromisso a ser assumido na Concretude da vida e a afirmação do Crer como "ethos" fundamental.
\end{abstract}

PALAVRAS-CHAVE: Juvenal Arduini. Destinação antropológica. Ética responsável e criativa. Educação. Existencialismo. Cristão.

\begin{abstract}
This article points to elements from two works of Juvenal Arduini and presents information from the author's life. Priest and educator, he discusses topics of interest and great relevance in his works "Destinação Antropológica" and "Ética Responsável e Criativa". His ethical-anthropological reflection is inserted both in the context of Brazilian education and in the context of higher education. Arduini believes that the man is responsible for his destiny and he is capable of answering his everyday problems and challenges from a personal point of view. The people obtain good results when they use the inter-communication. The man can contribute to a fair society expressing their identity through language including his capacity of silence. The author's Christian existentialism reveals his admirable capacity of synthesis between the real life and the belief as a fundamental "ethos".
\end{abstract}

KEYWORDS: Juvenal Arduini. Anthropological assignment. Responsible and creative ethical. Education. Christian existentialism.

\footnotetext{
${ }^{1}$ Especialista em Docência na Educação Superior (UFTM). E-mail: wsilva@prodepe.uftm.edu.br.
} 


\section{Introdução}

Juvenal Arduini é pensador denso, criativo, com inegável poder de síntese. Aliada à sua madura visão teológica, sua reflexão antropológico-filosófica é admirável, pois adentra com profundidade nas discussões relacionadas ao ser humano em suas mais diversas dimensões. Padre católico, Monsenhor Juvenal tem 91 anos de vida, com mais de 60 dedicados ao sacerdócio, com um intenso trabalho docente em várias universidades, palestras e conferências em vários lugares do Brasil, artigos em vários jornais e revistas brasileiras e internacionais, além de vários livros nos campos da Filosofia e da Teologia. Participa de várias Associações de Filosofia, de Pensamento teológico e de Literatura, em níveis nacional e internacional. Homem de pensamento, dedicou a maior parte de sua vida ao ensino universitário e ao trabalho junto aos jovens e docentes. Sua "Missa Universitária" reuniu diversas gerações de homens e mulheres, estudantes e profissionais das mais diversas áreas. Inclusive pessoas sem qualquer definição religiosa participaram dessas celebrações, atraídas pelo estilo acolhedor e amigo, e por suas homilias profundas e questionadoras. O ambiente celebrativo e os momentos em que recebia as pessoas para "conversas" e "confidências" tornaram-se fonte de encontro e resistência para perseguidos no período da ditadura militar. Outros textos poderão fazer justiça histórica ao retomar, por exemplo, o fato de o Padre Arduini ter sido diversas vezes "observado" por agentes do Serviço Nacional de Inteligência, que anotavam suas pregações e reuniam seus artigos em "dossiês".

O presente artigo aponta alguns elementos do pensamento de Juvenal Arduini, a fim de evidenciar sua contribuição, particularmente num momento em que muitas reflexões são feitas e em que, também quanto à realidade educacional, várias iniciativas são propostas nos campos da política pública.

Nas páginas seguintes são apresentados alguns elementos propostos por Arduini em duas de suas obras: Destinação Antropológica e Ética Responsável e Criativa. $\mathrm{Na}$ primeira, de caráter mais antropológico, o autor defende uma perspectiva filosófica do ser humano dotado de fundamental dignidade e de uma liberdade que o faz levantar-se contra tudo o que cerceia seus passos rumo ao pleno desenvolvimento a que se destina. Na outra, uma reflexão ética em diálogo com vários pensadores, Arduini questiona e propõe diálogo e busca de soluções, sempre de forma "responsável e criativa". Haveria uma a mais, Antropologia: Ousar 
para reinventar a humanidade, editada em 2002, que poderia ser apresentada como ponte entre as citadas. Como demandaria um espaço maior, e como os principais temas serão aqui considerados, não se tratará dela neste artigo. Entretanto, poderse-ia afirmar também nela a presença de um elemento que se tem mantido permanente na obra de Juvenal Arduini: a defesa de valores que, exigindo constante e atualizada atenção de sua parte, não o demoveu de sua obstinada opção pela vida, pela verdade e pela justiça. Espera-se, assim, que a análise dessas suas obras seja uma contribuição, em especial porque propostas por alguém que se tem revelado coerente e firme ao longo de sua vida. Na educação, talvez mais do que em outras áreas do conhecimento, uma reflexão de cunho ético, aliada à coerência do testemunho de vida, será sempre um "logos" oportuno!

Pretende-se apresentar uma possível leitura entre tantas outras, com certeza mais competentes e aprofundadas. Que este texto seja visto como uma reflexão partilhada, uma retomada de algumas citações de obras de inegável densidade e

vigor. É que o autor, para "tecer" seus escritos, lança mão de amplo conhecimento das mais diversas correntes filosóficas, dialogando com autores da antropologia, da história, da literatura, do direito, da economia, da sociologia e das artes, dentre outros, e, particularmente, manifestando densa visão teológica. O existencialismo cristão do autor seja visto nesta perspectiva, a do pensamento que olha a realidade e, nela percebendo o que é causa de "des-humanização", manifesta compromisso com conseqüente ação transformadora. Desde já, fica afirmada a ótica cristã de sua formação. Assim, na apresentação desta "leitura possível", deseja-se contribuir para destacar, nesses escritos de Juvenal Arduini, algo de sua reflexão éticoantropológica que possa auxiliar no necessário debate sobre a educação brasileira, em geral, e, particularmente, a que se desenvolve no ensino superior.

\section{O Homem, construtor de seu "Destino"}

Muitos têm falado sobre nossa "condição pós-moderna" de seres fragmentados, entranhados (e estranhados!) em sistemas que desconsideram a sede e fome de uma vida mais plena e carregada de sentido, que todos temos. $E$, caso alguém não manifeste tal necessidade, é que a vida alojou-se na aceitação pura e simples do sobreviver. Num contexto de globalização que a todos enreda em suas teias cibernéticas, a falta de tempo e um sentir-se deslocado são como pilares 
fragilíssimos em que se (des)estrutura a vida de todos e cada um - atingindo até mesmo remotas áreas rurais e comunidades tradicionalmente alijadas da "corrida do ouro" tecnológica. A saída parece ter sido a de propor que nos refugiemos no pequeno espaço de nossas inter-relações, de nos filiarmos a pequenos grupos de pertença, numa atitude que bem poderia chamar-se de "volta às tribos". Juvenal Arduini insiste numa antropologia que reconhece e defende no Homem a sua realidade mais radical de ser completo e sempre complexo na sua totalidade multidimensional. Afirma que

(...) o homem transcende todas as análises que o interpretam, por exaustivas que sejam. A consciência de sua grandeza há de fazê-lo responsável pela sua destinação histórica. É no confronto entre pulsões e liberdade, é na dialética da finitude e transcendência, é no encadeamento do terminado e interminado, que o homem consegue acender as tochas da história e iluminar a face do mundo, para a construção da utopia que ainda não concretizamos, mas que não desistimos de buscar. (ARDUINI, 1989, p. $55)$.

Inconformado com pensamentos concebem os seres humanos como "destinados" a uma Moira ${ }^{2}$ de cujas mãos fiandeiras não se pode escapar, Arduini lança uma vigorosa convocação a que tomemos em nossas mãos uma autêntica "Destinação", em que cada um, e a Humanidade toda, possa assumir o "destinarse", processo que parte da basilar "des-destinação" (ARDINI, 1989: 166) e alcance propositiva "re-destinação". Com efeito, criticando a escravidão, histórica mácula da qual se beneficiaram gerações e gerações de "bons cristãos latifundiários" no Brasil, o autor a apresenta como elemento cultural que tende a perpetuar-se. E afirma que

Se há o não-ser que nega o ser do homem brasileiro, há também o ser do homem brasileiro que emerge para afirmar-se e expelir o não-ser que o deteriora. O não-ser que está alojado na injustiça, no latifúndio, na escravidão, na pobreza, des-destina o homem brasileiro. E o ser que se expressa na justiça, na liberdade, na igualdade, na redistribuição da terra, re-destina o homem brasileiro. Emancipada pela dialetização do ser, a positividade dos dominados conseguirá superar a negatividade alastrada pelos dominadores do mundo. O universo humano modificado pelo não-ser é fator de des-destinação. Mas o povo empobrecido ontologizado pelo ser é agente de re-destinação. (ARDUINI, 1989, p. 172).

\footnotetext{
${ }^{2} \mathrm{Na}$ mitologia grega, a deusa encarregada de "fiar" o destino dos seres humanos.
} 
De forma admirável, Juvenal Arduini, dialogando com Heidegger, serve-se da Fenomenologia deste, que indaga "pelo sentido do ser, especialmente pelo sentido do ser que se questiona a si mesmo, o homem" (ARDUINI, 1989, p. 151). Entretanto, ilumina com sua consciência hermenêutica ${ }^{3}$ de pensador brasileiro e latino-americano a ontologia que vê o profundo de cada ser e a dirige para o ser coletivo, o ser povo, o todo de uma identidade cultural que urge afirmar-se, "redestinar-se". Crítico incansável dos que proclamam teorias conformistas do "Fim da História"4, dos que se curvam diante do poder do "Império", ele renova a cada texto sua "opção preferencial pelos pobres", pelos não-considerados, pelos descartáveis e descartados do neo-liberalismo alardeado triunfante. E ergue sua voz para afirmar o que poucas inteligências têm feito. Urge abertura do mundo da educação para ouvir a pensadores tais, comprometidos e engajados na defesa da identidade e "potencialidade" de cada povo e defensores de uma esperança que não seja ópio a entorpecer as consciências:

\begin{abstract}
Ainda há esperança porque a história não terminou. O homem brasileiro ainda pode reapropriar-se de seu ser e resgatar o sentido de sua vida, porque a erosão produzida pela "cultura da opressão" não lhe extinguiu o poder de redestinação. (...) $\bigcirc$ povo tem potencialidade para mudar 0 destinamento opressor, porque é torrente emancipatória. E começa a emancipar-se quando começa a descrer dos poderosos e a confiar em suas próprias forças. A consciência crítica das servidões vividas, há de levar o homem brasileiro a ser mais decidido e mais arrojado para re-destinar-se e re-assumir-se como insubstituível sujeito histórico. (...) Estamos diante de um povo que foi inferiorizado, mas que não é inferior. (ARDUINI, 1989, p. 179).
\end{abstract}

Não se pense, porém, que o pensamento de Juvenal, na dimensão teológica filiado à Teologia da Libertação, dirige-se tão-somente aos pobres, "incultos e iletrados" - como se tal opção fosse algo a desmerecer sua obra: ainda que mais à

\footnotetext{
${ }^{3}$ Entendemos tal consciência no seu sentido mais amplo de "leitura" e interpretação da realidade, não excluindo a tarefa de des-ocultar o seu sentido por vezes velado.

${ }^{4} \mathrm{O}$ artigo de Francis Fukuyama, politólogo nipo-americano, com o título "The end of history" apareceu em 1989, na revista norte-americana The nacional intereset. Em 1992, ele lançou o livro "The end of history and the last man", editado no Brasil quase simultaneamente no mesmo ano, como o título "O fim da história e o último homem", pela Rocco, traduzido por Aulyde Soares Rodrigues. Arduini, ao dizer que "Ainda há esperança porque a história não terminou", está se posicionando diante deste livro, o que indica sua "sintonia" com o que é produzido em termos de reflexão, aqui e fora do país.

${ }^{5}$ HARDT, M. e NEGRI, A. Império. Rio de Janeiro. Ed. Record, 2001 (Tradução de Berilo Vargas)
} 
frente ele vá tratar especificamente do "mundo universitário"6 e, em geral, da educação, ele antecipa dizendo que

Trabalhadores de todas as profissões, educadores comprometidos, estudantes conscientes, intelectuais orgânicos, pesquisadores lúcidos, artistas engajados, políticos ligados às causas sociais, jovens e adultos com militância popular, comunicadores independentes, cristãos libertadores, já começaram a romper o cerco da cultura da opressão para se re-destinarem ao ciclo da cultura da libertação. (ARDUINI, 1989, p. 178).

Todos esses "re-destinadores" são chamados a lançar-se corajosa, decidida e generosamente neste movimento de reestruturação da sociedade. Os demais, que tenham a grandeza de alma e honestidade bastante para responderem ao "Até quando funcionaremos como clientes do oportunismo? Até quando evitaremos comprometer-nos?” (ARDUINI, 1989, p. 138) Inescapável e definitiva questão, esta!

Dirigindo seu olhar para o mundo da educação, para depois tratar da realidade universitária, Arduini propõe alguns elementos de reflexão que contribuem para fundamentar muito do que $u_{r g e}{ }^{7}$ ser feito, em vista de um processo educativo que contribua para uma formação mais plena de nosso povo. Para ele, que recolhe da tradição humanista as sementes de seu pensamento sobre a educação, educar e educador praticamente se fundem. Como que assumindo a antiga máxima do agere sequitur esse (o agir segue o ser), fiel à sua raiz aristotélico-tomista, ele afirma que educar

(...) é explicitar o que está latente, é ativar potencialidades. Educar não é produzir artefatos. É 'orientar', que significa amanhecer, surgir, nascer. Educar é originalizar, é fazer crescer de dentro pra fora, é ajudar o novo a emergir. Ser educador é ser 'oriente', para ir aclarando consciências e destinos. (ARDUINI, 1989, p. 201).

Por isto, propõe que o educador evite negar as "duas posições que negam o espírito pedagógico": o autoritarismo, de quem impõe e se posiciona praticamente contra o educando, e a passividade do espectador, que não se inclui, não participa efetivamente, que se limita aos aspectos técnicos e "profissionais". Para Juvenal

\footnotetext{
6"Mundo universitário" e "mundo da educação" referem-se, no autor, a uma realidade mais ampla que transcende a simples situação local, regional ou mesmo nacional. Pode incluí-las, mas geralmente não se limitam aí.

${ }^{7}$ Outro elemento constante se sua obra é o sentido de urgência, em contraposição ao adiamento descomprometido.
} 
Arduini seria plenamente educador quem conseguisse apresentar-se como "oriente maiêutico", quem seguisse os passos do "parteiro" Sócrates e conduzisse seus alunos à prática perguntadora, prática que os revelasse cada vez mais humanos, uma vez que "o homem se caracteriza pelo perguntar", e "o autêntico educador (é quem) pro-voca ${ }^{8}$ a reflexão do educando. É oriente maiêutico a despertar consciências e a clarear roteiros." (ARDUINI, 1989, p. 202)

$\mathrm{Na}$ verdade, as várias atitudes possíveis nos educadores revelam pertença aos mais diversos modelos pedagógicos. Tais modelos acham-se entranhados no fazer pedagógico, de uma maneira mais ou menos consciente, em cada educador. Juvenal Arduini expõe e questiona as propostas que se limitam à transmissão conteudística que, a seu ver, mais parecem "ensilagem pedagógica"9; aponta as que pretendem preparar o aluno para uma "integração" maciça ao que está normatizado e estabelecido, mas que não admitem qualquer discordância; e mostra a perversão do modelo tecnológico, que, ostentando roupagem moderna dos recursos e inovações tecnológicas, não vão além do ato de fazer. Com efeito, a transmissão pura e simples, diz o autor, não pergunta "para quê e para quem fazer" e, desta forma, "mutila a finalidade humana e social." Tal modelo se esquece, de modo injustificável, da "significabilidade" inerente à técnica, no sentido de que toda obra humana tem destinação histórica. Entretanto, é na apresentação do "Humanismo Pedagógico" que Juvenal, com profunda sensibilidade humanística, dirige de modo mais detido sua análise. De fato, os fundamentos do humanismo estão enraizados nos valores e princípios da pessoa, da liberdade e da responsabilidade, sendo o homem o sujeito e fim da educação. Proclamá-los não é o problema. O que se deve questionar é a conveniente convivência (conivência!) de quem defende "a dignidade da pessoa como valor universal", mas tolera e mesmo justifica "a situação de miséria degradante em que se encontram concretamente muitos seres humanos,

\footnotetext{
${ }^{8}$ Em Juvenal Arduini é constante o recurso da hifenização para "acordar" o leitor para um sentido mais "radical" do que propõe. Assim é que encontramos com freqüência os verbos "pro-vocar", "redestinar", "des-destinar".

${ }^{9}$ Do educador Paulo Freire é consagrado o conceito de "educação bancária", para falar desta prática educativa (?) que não vai além da transmissão, pura e simples. Importa ouvir pensadores que alertam para um processo educacional que, verdadeiramente, conduzam o ser humano a um conhecimento cada vez mais pleno de si mesmo e a uma ação que transforme sua própria realidade, desde o nível pessoal e familiar a níveis mais profundos das dimensões social, política, econômica, cultural e religiosa.
} 
inclusive muitos educandos. ${ }^{10 "}$ Uma vez que tais valores defendidos pelo humanismo devem ser traduzidos em "concretudes históricas e sociais", Juvenal lança severa crítica e aponta caminhos de superação de tal incoerência, dizendo que

Em geral, todos aceitam teoricamente os princípios humanistas, até os burgueses, os dominadores, os torturadores. É preciso mostrar que o ser é mais do que o ter, não para dispensar o 'ter', mas para incluí-lo como prérequisito do 'ser'. Precisamente porque o ser vale mais do que o ter, é que o ser exige que a pessoa tenha salário suficiente, tenha moradia, alimento, vestuário, remédio, tenha terra, direitos fundamentais, e outras coisas mais. E a partir desta colocação, veremos que muitos 'humanistas' começarão a desertar do tão propalado humanismo, para defenderem posições totalmente anti-humanistas. (ARDUINI, 1989, p. 203)

Nesta linha de raciocínio e neste nível de compromisso, Arduini busca desmistificar ainda outras propostas pedagógicas que apresentam "conteúdo arcaico", com "sabor paleológico", ou conteúdos que ele caracteriza como "neoconservador" ou "reformista", simplesmente. E se posiciona a favor do que ele considera "desafio crucial" (ARDUINI, 1989, p. 205): a realização de indispensável "salto pedagógico", a ser alcançado pela "educação transformadora", que "pretende mudar a escola e a sociedade". Numa linha de coerência com a perspectiva que defenderá ao tratar da missão educativa universitária, Juvenal afirma que

A questão nevrálgica não é preservar a educação que justifica o que aí está, mas requisitar a educação que contribua para instaurar projeto social que corporifique as reivindicações vitais das camadas populares. Realidades diferentes, e até opostas, pedem dinamismos educacionais diferentes. (ARDUINI, 1989, p. 206).

Juvenal Arduini percorre os vários espaços de degradação e aviltamento da dignidade humana, presentes e co-existindo ao lado de ilhas de consumo e conforto $^{11}$ que batem na face dos empobrecidos do país. Fala da histórica persistência do elitismo na educação brasileira, que proclama o valor da liberdade

\footnotetext{
${ }^{10} \mathrm{O}$ autor não pretende, certamente, afirmar que educandos não seriam seres humanos! Lembremonos dos milhões de seres humanos que não têm a oportunidade de serem "educandos", no sentido de acesso à educação formal...

${ }^{11}$ No mar revolto das enormes dificuldades para a sobrevivência da maioria, o fato de alguns se encastelarem em tais "ilhas" é uma agressão à dignidade humana. Ou seria totalmente irrelevante o fato de alguns usarem calças que custam o que um(a) trabalhador(a) não ganharia um ano inteiro?! As grandes questões da educação passam pela resposta a estas outras... A inconseqüente pergunta "O que que tem?", diante de uma realidade tal, seria indicativo de grosseira insensibilidade!
} 
da pessoa, mas não inclui o seu equivalente social: a igualdade. E afirma que é "por demais sintomático que 'classe' seja assunto proibido na escola." (ARDUINI, 1989, p. 211) Proibido pelos "beneficiários da exploração de classes fracas", porque esta temática seria "subversiva e atiçadora de violência"; e tema praticamente tabu por parte dos educadores, o que poderíamos dizer que é bem mais grave, pois o não incluir tal discussão na prática educativa é indicativo de falta de consciência crítica. $\mathrm{Na}$ verdade, os professores são considerados (consideram-se!) como classe média, por "sua cultura e posição na sociedade". Porém, o autor lembra que, de acordo com o IBGE, classe média é a que recebe de 6 a 20 salários mínimos; e pergunta: "quantos professores de primeiro e segundo graus percebem acima de 6 salários mínimos?", informa(n)do que em Alagoas, em 1988, 70\% dos municípios daquele estado pagavam aos seus professores remuneração que não alcançava o salário mínimo ${ }^{12}$.

Juvenal Arduini apresenta a Universidade como autêntico "campus antropológico", em que o pensar crítico e "desatado" (ARDUINI, 1989, p. 226) não se furtaria inclusive a tratar do "sentido de Deus". Coloca esta questão perguntando se levantá-la não seria "legítimo", no "processo universitário", para defender que

a questão do Transcendente não é anomalia epistemológica. É, apenas, continuar a questionar, a buscar o sentido em ritmos cada vez mais intensos, enquanto houver ser. Trata-se de prolongar, coerentemente, 0 fenômeno da transcendência, que se inicia no momento em que o homem conversa com o próprio homem. (ARDUINI, 1989, p. 226)

Juvenal posiciona-se quanto à "Morte de Deus", que persiste em tantos ambientes "universitários", herdeiros da demolição nietzschiana, contrapondo-se à perspectiva heideggeriana - esta, quase que inexistente nas (pretensamente!) científicas, objetivas e neutras produções acadêmicas. $O$ autor reconhece a contribuição de Nietzsche, que "reacende a subjetividade para que o ser humano seja o criador de si mesmo", mas lembra que este, "ao priorizar o 'valor', (...) esqueceu e ocultou o 'ser'." (ARDUINI, 1989, p. 228)

\footnotetext{
${ }^{12}$ Resta voltarmos àquele Estado e àquela Região para conferirmos as efetivas mudanças operadas, após 20 anos distanciados "daquela" realidade! E nas demais regiões e lugares considerados "de excelência", como estaria a situação geral da educação e a dos educadores? Este tema se tem constituído em objeto de pesquisa, discursos políticos e elaboração de muitas de nossas leis em matéria educacional. Mesmo em tempos de investimentos em somas inéditas na educação, como vemos no atual Governo, as questões de qualidade do processo educativo como um todo, bem como as relacionadas às condições de vida e trabalho dos professores não podem ser jamais desconsideradas: e estas sempre ligadas àquelas!
} 
Num dos poucos momentos em que explicita a dimensão teológica em seu texto, Juvenal Arduini refere-se ao testemunho do Mestre Jesus que, se o faz quando se refere aos educadores de um modo geral, podemos ver seus ecos nas entrelinhas do que o autor diz quanto à docência universitária. Com efeito,

(...) aqui, lembramos Cristo que escandalizou muita gente de seu tempo, sobretudo os detentores do poder. 'Escandalizou' porque curou enfermos em dia de sábado e subordinou o legalismo sabático ao valor maior que é o homem. O Mestre evangélico suscitou sustos e cóleras, ao esfarelar tradições ritualistas para restaurar e ampliar os grandes valores da vida. Já é hora de reivindicar a educação madura que refugue os alienados "valores" da servidão mascarada, e tenha a autonomia crítica para assumir resolutamente os autênticos valores da destinação libertadora. (ARDUINI, 1989, p. 213).

Encontraremos nos mestres universitários a coragem para tal atitude "escandalizadora"? Juvenal Arduini, como de seu costume e indicativo de sua característica pessoal, encerra seu "Destinação Antropológica" falando de Esperança, virtude de quem se arrisca, de quem se "des-prende", solta as amarras porque "caça uma resposta", busca "o salto antropológico que possibilite ao Todo Humano viver e crescer na igualdade autônoma e na convergência solidária." (ARDINI, 1989, p. 279) Se vamos ou não encontrar o desejável e tão adequado "escândalo", parece não ser esta a questão fundamental: importa que o educar esteja carregado desta disposição para o partir, para o avançar e o crescer, não se conformando jamais com o imobilismo, pois este pode levar ao congelamento e a "vegetar na mediocridade".

A outra leitura a que nos propomos justifica-se pela atualidade do tema, também caro a Juvenal Arduini. Trata-se de assunto que circula nos midiáticos acontecimentos da ordem do dia no Planalto Central do país e se acha nos trabalhos inocentes de nossas crianças, que rabiscam suas primeiras letras: a freqüente e tão (des)considerada "ética"!

\section{Ser Humano: chamado à Responsabilidade e à Criatividade}

Nesta seção, pretende-se considerar em especial a função docente, o desafio do cotidiano do professor em sala de aula, tanto para alunos da educação infantil 
como para os de nível superior e pós-graduados. O ser humano é, filosoficamente, considerado como "ser de comunicação". Pois uma das questões que mais inquietam o professor é a de saber até que ponto tem conseguido, no seu "fazer pedagógico", alcançar o que muitos têm proposto como verdadeira expressão de sua profissão (e "missão"): a comunicação didática. Para isto, haverá de estar sempre atento ao enorme elenco de possibilidades e recursos para que consiga comunicar não só o conteúdo específico de sua formação, mas os valores e seus pontos de vista a respeito do "currículo maior", a realidade humana que a tudo envolve. Neste sentido, importa que tais fundamentos filosófico-valorativos da didática orientem e inspirem olhares mais amplos sobre as instituições e demais estruturas educacionais, a partir da ação concreta dos docentes.

Um dos aspectos que mais desafiam o docente em sua ação diária é o caráter não-verbal que toda comunicação encerra, inclusive a que ele realiza em sala de aula. Costumeiramente, a docência é vista como "o ofício da palavra". Por isso serão apresentadas, a modo de reflexão, algumas notas sobre o olhar, a face e o silêncio, constantes do mais recente livro ${ }^{13}$ de Mons. Juvenal Arduini: Ética Responsável e Criativa. A antropologia e a ética, das quais o autor lança mão para convidar-nos a um engajado diálogo, são como dois fortes esteios a sustentar a videira de onde o professor, junto a seus alunos, poderá colher os saborosos frutos da alegria - ainda que palavras não sejam ditas!

Como nos livros anteriores, Arduini trata de temas como a personalização, a ética, a dignidade e a intercompreensão; apresenta de forma belíssima a síntese de muitos pensadores, como Ernst Bloch, Paul Ricoeur, Gadamer, Deleuze e Habermas; mas convida a um verdadeiro "dobrar os joelhos" diante da realidade mais profunda do Ser humano, sua "constituição ôntica". Exatamente aqui se insere uma contribuição e um elemento que diferem Juvenal Arduini de pensadores que não consideram o Transcendente - no sentido mais amplo de considerar também a dimensão religiosa: o seu é um existencialismo que, na herança de Gabriel Marcel, volta-se para a defesa de uma humanidade em que o "ex-istir" se faz em coerência com o seu ser mais profundo. $O$ homem existe mais plenamente quanto mais humano se torna. Por isto, tudo o que o impeça de realizar tal obra deve ser

\footnotetext{
${ }^{13}$ Em Uberaba, realizou-se o lançamento no dia 19 de novembro de 2007.
} 
vigorosamente combatido, caso contrário o que teríamos seria o campear da "deshumanização" - outro tema caro ao autor!

\section{O Olhar}

Quando fala desta complexidade chamada pessoa humana, verdadeiro "enigma", o autor apresenta múltiplos aspectos e dizeres a respeito do olhar que, de acordo com a enumeração em contrapontos que apresenta - reconhecido estilo seu! -, revela o que há de mais profundo e bonito, mas também sórdido e mesquinho. É que

Além de ver, o olhar fala. O olhar ensina muito. Mas nem sempre descobrimos a linguagem do olhar. Às vezes, ficamos apenas no ver, e desperdiçamos a fala do olhar. É preciso cultivar a fala do olhar. O olhar não faz estardalhaço. Há olhos fechados que falam mais do que olhos abertos. As reações do olhar falam silenciosamente. (...) O olhar é uma linguagem viva e também inquieta. O olhar fala por si mesmo. (ARDUINI, 2007, p. 108)

$\mathrm{Na}$ relação de ensino-aprendizagem devemos considerar sempre os dois principais sujeitos que se inter-comunicam, professor e aluno(s), os quais devem sentir-se desafiados a responder, cada qual por si, até que ponto o desafio encontrado em um olhar assim, carregado de sentido, é considerado no cotidiano de sua "vida escolar". Professor e aluno(s) têm assim uma referência para uma honesta e decidida auto-avaliação! Poderíamos, desta forma, compreender melhor nossa própria realidade pessoal, bem como a dos demais com quem interagimos e, assim, "ousar para reinventar a humanidade"14.

\section{A Face}

Além de apontar a força que encerra o olhar, Juvenal nos convida a refletir sobre este verdadeiro mistério, "carregado de sentido", que é a face humana. Ela "é presença. Está exposta a todos. Pode ser vista, pode ser comentada, pode ser seguida." (ARDUINI, 2007, p. 125) Diante de tal procissão de faces, das que atraem, que levam ao crescimento e à libertação, e daquelas que deprimem,

\footnotetext{
${ }^{14}$ Título do livro anterior, de Juvenal Arduini, editado em 2002, pela Editora Paulus.
} 
agridem e afugentam, importa buscar o seu significado maior, suas "mensagens intrigantes". Para isto, o autor nos adverte que "é preciso ser hermeneuta perspicaz para interpretar o sentido da face humana", pois ela "expressa a identidade da pessoa." O autor, cristão que é, insere em sua obra, a modo de semente, uma nota teológica, como a indicar que a ciência antropológica e o discurso ético nada perdem ao abrir espaço para uma humanidade que se abre ao Transcendente: "A face humana tem muito a dizer. Por isso, é preciso iluminar a face humana com a transparência da Face de Deus. E, assim, a face humana se tornará, cada vez mais, clareira inapagável." (ARDUINI, 2007, p.126)

O livro de Mons. Juvenal se encerra logo após considerar a fascinante carga de significados escondidos na face humana. $E$ isso com a instigante provocação: "Para onde vamos?" Na altura de seus 90 anos de vida, recém-completados, ele se posiciona a favor de um urgente "Reumanizar": "É hora de partir para recriar a nova humanidade. Reumanizar é o renascer da dignidade hermenêutica." (ARDUINI, 2007, p. 132).

\section{O Silêncio}

Segundo a ordem proposta pelo autor, ao falar da linguagem não verbal, o silêncio veio antes dos elementos recém-apresentados. No entanto, optou-se por subverter o índice apresentado, aceitando a provocação feita por Juvenal Arduini nas últimas quatro páginas de seu livro. Para todo o educador que se propõe com lucidez a comunicar didaticamente seu conteúdo - a si próprio, inclusive! -, já seria de grande mérito fazê-lo a partir do olhar e da leitura atenta da face de seus alunos. Por isso, falar, somente agora, sobre o silêncio, busca o sentido de valorizar ainda mais esta real prática de comunicação.

Numa sociedade da profusão de imagens e sons, urge considerar a advertência feita por Guimarães Rosa, único autor brasileiro citado por Juvenal: "No silêncio nunca há silêncio." (ARDUINI, 2007, p. 101) O silêncio é tão carregado de sentido como o ventre feminino, terra fértil pronta a acolher Nova Vida a brotar, a um só tempo frágil e tão potente. É que, nas suas múltiplas formas, ele "tem seu modo próprio de falar", e nele "mora a antropogênese, a gênese do ser humano." (ARDUINI, 2007, p. 101). 
Embora o silêncio leve muitos ao pavor, fugir dele "é fugir de si mesmo, é ter medo de encontrar-se." (ARDUINI, 2007, p. 102) Na mais legítima tradição filosófica, somos levados a lembrar Sócrates, para quem o auto-conhecimento era o caminho de afirmação da própria identidade e base para o conhecimento do Outro, das Coisas e do Mundo. Juvenal Arduini indica, em sua reflexão, o que há de grande, construtivo e nobre no silêncio, além de referir-se ao que esta linguagem revela de desprezível, estéril e vil.

Não deve ficar sem resultados, para a consciência de um(a) educador(a), a afirmação feita por Arduini de que o silêncio "é o lugar do encontro com os outros", e que "Assumir o silêncio é mais importante do que gargalhar nas praças." (ARDUINI, 2007, p.102) Por encerrar riqueza tão grande é que, entretanto, "Não devemos confundir silêncio com hermetismo e individualismo". (ARDUINI, 2007, p. 102) Bela é a forma como o autor, a seguir, encerra este tema ao dizer "Não espantemos o silêncio. Perder o silêncio é perder-se."

\section{O Educador e a linguagem não-verbal}

De acordo com o que foi dito acima, podemos perceber que muitas das dificuldades enfrentadas pelo profissional da educação poderiam encontrar solução em caminhos outros que não se limitassem às velhas respostas que se centrassem na figura do professor, como autoridade máxima e exclusiva, ou às "novas" propostas que centram praticamente no aluno toda a possibilidade de sucesso do processo educacional.

A linguagem não-verbal, quando valorizada pelo docente em sua comunicação didática, é realidade que exige estudo cuidadoso, fundamentação responsável, que de modo algum pode ser desconsiderada na relação educativa. $E$ valha ao educando o que se afirma com relação ao professor. Possamos, todos nós, "professores" e "alunos", nos matricularmos na Escola dos Gestos, Movimentos e Feições. E não nos passe despercebido o silêncio, no muito que este tem a nos dizer sobre o "Eu" e "os Outros", quando do estabelecimento do "agir comunicativo". Uma autêntica filosofia da linguagem irá sempre considerar todas as formas possíveis de o homem comunicar, seja a si mesmo, as coisas e sua visão de mundo. E a educação certamente quedaria empobrecida caso não considerasse tal perspectiva filosófica! 


\section{Considerações finais}

Juvenal Arduini foi apresentado nestas páginas como existencialista cristão. Não foi nossa intenção discutir propriamente a desafiadora problemática das interrelações possíveis entre o(s) existencialismo(s), nem nos determos sobre as relações que este(s) estabelece $(\mathrm{m})$, por exemplo, com o Personalismo, outro veio de formação de Arduini. Um estudo mais detido sobre sua obra, a qual inclui artigos em jornais e revistas e inúmeros discursos e homilias, poderia indicar como este autor transita entre estas várias correntes e se insere na mais legítima tradição paulina do "examinar tudo, ficar com o que é bom" (I Ts 5,21). O seu é um existencialismo que não se fecha à herança aristotélico-tomista, outra coluna forte de sua formação, mas que mantém escuta e abertura ao "novo", ao que vai surgindo de "atualizado": novos desafios exigem sempre novas respostas! No ambiente eclesiástico não falta quem tal pensamento como traição. Não seria de estranhar se no ambiente acadêmico esta postura de Juvenal Arduini fosse vista como grosseiro ecletismo, como pensamento menos "sério" ou "desautorizado" - uma vez que o autor não procurou granjear títulos da Academia!

Padre responsável pela formação de novos padres nos tempos do Concílio Vaticano II, na década de 60 do século passado, Juvenal manteve em sua vida constante aggiornamento (atualização). Este termo, usado pelo papa João XXIII, que convocou os bispos de todo o mundo para aquela importante reunião, foi um dos grandes objetivos a ser empreendido pela Igreja que, historicamente, não havia dado resposta ao "mundo do trabalho" e ao "mundo da inteligência". Não tinha o que dizer, na verdade, aos operários e aos intelectuais! A Teologia latinoamericana, a chamada "Teologia da Libertação", inegável presença na obra de Juvenal Arduini, foi pensada e proposta para responder à realidade de opressão com a revolucionária proposta de unir "fé e vida", religião e compromisso políticosocial. Aos educadores valeria refletir e perceber, por exemplo, marcas deste pensamento na chamada Pastoral da Educação. Mas isto seria objeto de pesquisa posterior.

Em "Destinação Antropológica", "destinar" tem o sentido de apontar os passos numa determinada direção, quando a pessoa se decide por determinar sua própria existência, consciente e inconformada com determinações externas. Na perspectiva cristã do autor, isto se revela por ele ir além da tradicional metafísica aristotélico- 
tomista, essencialista e "desencarnada" das condições concretas da existência humana. Se há uma "essência humana", esta não autorizaria grandes afirmações discursivas sobre dignidade e demais valores humanos, pura e simplesmente: urge fazê-los verdade histórica - tema caro ao autor, onde ele "areja" o antigo pensamento da Igreja!

Em "Ética responsável e criativa", afastando-se de qualquer doutrinação, Arduini propõe exercício de um lúcido e aberto "diá-logo", exatamente por ser a ética uma prática que engaja e reclama compromissos. Há neste seu livro a defesa de uma ética que seja expressão de um honesto e constante diálogo, prática que deve ser cada vez mais freqüente e competente. Neste sentido, a ética deste autor é lucidamente apresentada em contexto político, como valor indiscutível para a vivência de uma democracia cada vez mais plena e participativa.

Uma leitura que fizesse maior justiça ao autor deveria abrir mais categorias de análise, o que nos sugere dizer que mais e mais contribuições para a compreensão e divulgação de seu pensamento poderiam acrescentar elementos de profundidade e maturidade à Academia, de um modo geral, e aos docentes de nível superior, em particular. Inestimável presença, a de Juvenal Arduini, jovem e arejado, ainda que com seus alvíssimos cabelos. A filosofia da educação há de beneficiar-se de suas obras. Num mundo em que escasseiam as referências de vida, mais que dos grandes discursos - verdadeiro vício, tanto mais "divinamente titulados" seus autores! -, os educadores poderiam ao menos procurar abrir-se ao pensamento e obra deste autor, bem como à sua humilde, silenciosa e inegável coerência de vida. Não seria o que deveríamos buscar em nós mesmos, o que exigimos dos outros e o que todos esperam de nós?

\section{REFERÊNCIAS}

ARDUINI, J. Destinação Antropológica. São Paulo: Paulinas. 1989.

Ética responsável e criativa. São Paulo: Paulus. 2007.

Antropologia: ousar para reinventar a humanidade. São Paulo: Paulus. 2002. 